\title{
An Exploratory Study for Perceived Advertising Value in the Relationship between Irritation and Advertising Avoidance on the Mobile Social Platforms
}

\author{
Xiaolong Wei \\ Chonnam National University \\ fenglangzi0925@126.com
}

\author{
Ilsang Ko \\ Chonnam National University \\ isko@ chonnam.ac.kr
}

\author{
Nan An \\ Chonnam National University \\ Annan1994@ naver.com
}

\begin{abstract}
This study delves deeply into advertising avoidance research and redefines the uses and gratifications theory $(U \& G)$ as divided into (a) convenience $U \& G$, (b) content $U \& G$, and (c) social $U \& G$ to conduct an approach to alleviate the degree of advertising avoidance on the mobile social platforms. To carefully study the forming framework of advertising avoidance, we extract the factor irritation considered to directly impact on avoidant intention induced by perceived intrusiveness and privacy concerns. As an important previous factor in advertising research, we also test the moderating effect of perceived advertising value between irritation and advertising avoidance. Findings show that ubiquity takes a negative role on mobile social platforms and tailoring also takes different roles on perceived intrusiveness and privacy concerns; unfortunately, content $U \& G$ consist of advertising informativeness and entertainment didn't find any significant effect; in contrast with previous study, social $U \& G$ as social interaction and social integration also show some different roles but is ambiguous. However, the positive relationship of perceived intrusiveness, privacy concerns, irritation, and advertising avoidance has been confirmed again although with a pity of insignificant moderating effect of perceived advertising value. Management issues, theoretical contributions, limitations and future study are discussed as follow.
\end{abstract}

\section{Introduction}

According to one report [3], there are 6 billion smart phone users worldwide, reflecting $87 \%$ dissemination, and the market scale of mobile advertising has expanded as well. A census on online advertising from Korea's Ministry of Science, ICT and Future Planning and Internet Security Agency reported that mobile advertising market scale was 1351.8 billion Korean won in 2015, in 2016 had got to 1786 billion Korean won, and predicted that it will get to
2039.7 billion Korean won in 2017. With a sharp mobile advertising market scale's increase, however, some research recently argue that there is a decreasing effectiveness of internet advertising, a phenomenon referred to "banner blindness" as a nightmare which can be devastating for advertisers and companies [11, 68]. In a research on effectiveness and attention to banner ads, Lee and Ahn argued that internet as an advertising media confront with an especial issue is ad avoidance [41]. Recently, some studies also reported that general consumers take a negative attitude toward advertising on internet [26, 34, 41, 58, 63]. Ducoffe' web advertising model [20] recommended that irritation and perceived advertising value as important previous factors for attitude toward web advertising. Combing theory of reasoned action [1], we extracted irritation as a negative attitude considering it would directly impact on the intention of advertising avoiding. So, the first research question we address in this paper is that how the relationship will exist between irritation, perceived advertising value and advertising avoidance on mobile social platforms. Previous research for advertising avoidance on mobile social platforms is very scant, to complement this pity, we conducted a forming framework to carefully understand advertising avoidance occurs in mobile social media by exploring the structural relationship between irritation in addition to perceived intrusiveness $[6,12,13,22,34,40,66]$, privacy concern $[6,8,25,47,51,59,67]$ and advertising avoidance with the moderating effect of perceived advertising value.

U\&G theory has been widely adapted to studying the motivations for using digital media and online advertisement's accepting. But research applying $\mathrm{U} \& \mathrm{G}$ to advertising avoidance on mobile social platforms is very few, so considering the features of mobile social media like ubiquity, tailoring, socialization to study advertising avoidance is necessary. In this paper, considering advertising's fundamental ability of informativeness and entertainment, we redefine $U \& G$ dividing into convenience $U \& G$ as ubiquity and tailoring, content $U \& G$ as informativeness and entertainment, social $U \& G$ as social interaction and social integration to 
improve the utilization of $U \& G$ on mobile social advertising' research. So another underlying research question in our research is: By utilizing U\&G, can we conduct an appropriate approach to alleviate the degree of advertising avoidance on mobile social platforms? Recent research argued that ubiquity has a negative effect on internet advertising [12, 51], tailoring consist of customization and personalization also take a different role for advertising accepting [43] More especially, socialization as social interaction and social integration for studying advertising is so simple and ambiguous [52, 61, 62, 70]. To illuminate the relationship between them in detail by developing $\mathrm{U} \& \mathrm{G}$ for studying advertising avoidance on mobile social platforms will take both theoretic and managerial contributions.

\section{Literature Review}

\subsection{Advertising in mobile applications}

Smart phone advertising campaigns vary widely, including using mobile applications to communicate with consumers closely [44]. Mobile applications have the unique feature of being ubiquitous, in contrast with PCs [2, 51]; that is, information can be accessed from any location at any time, which has been highlighted as the most important and distinctive asset of mobile devices. Some research on ubiquity has argued that with no consideration of consumers' privacy, spam messages make consumers feel threatened and lead to negative attitudes, whereas supplying consumers with relevant messages at the right time, even if some private information is exposed, leads to positive attitudes [51]. And so many studies based on mobile services have studied personalization and tailoring for advertising [37, 56, 43]. As two types of information tailoring, customization and personalization has been discussed frequently in the field of communication. But research emphasizing the opposite role of customization and personalization taking for advertising on the mobile platforms is very scant [43]. A research on location-based advertising, Lee et al. empirically found that customization and personalization have different effects on attitude toward location-based advertisement on the mobile services. Personalization emphasizes system-initiated tailoring whereby the system automatically tracks personal information and delivers ad content that matches consumer preferences will induce some rather passive attitudes, whereas customization emphasizes user-initiated tailoring that allows users to choose their ad categories based on their own preferences and leads to more positive attitudes. Therefore, in this paper, to more clarify the role of ubiquity and tailoring for advertising on mobile social platforms, we redefine convenience U\&G with ubiquity and tailoring to explore the relationship with perceived intrusiveness and privacy concerns.

\subsection{Advertising in SNSs}

Among smart phone advertising strategies, one method is using SNS to form close connections with consumers [44]. In contrast with traditional ad media, social media has features such as allowing sharing, connecting, participating, and communicating, and with these features, it can offer more interaction with consumers to generate new and transparent environments. Focusing on user connections can generate free content that users transform and share, shifting from one-to-one marketing to one-to-many viral marketing [35]. Li et al. [45] had successfully operated a study by applying the theory of dynamic social influence and celebrity endorsement for forming a social advertising system called "SEAD (social endorser-based advertising)" to improve the advertising effectiveness and efficiency in Facebook. And some research [5, 7] argued that advertising strategies like social context and sponsored stories in SNSs are more effective than traditional approaches. However, Li et al. [45, 46] suggested that there existed some challenges for SNS advertisements: (1) the way selected an appropriated celebrity is always a problem (2) it is hard to recommend new items when there are no related comments or rating records (3) the intent of consumers on SNSs is not to purchase products and (4) the social context attached to the advertisements can't resonate with the audience sufficiently and powerfully. So it could also induce advertising avoidance easily in social media. In a research on Social TV web sites video advertising, Pagani and Mirabello [52] defined consumer engagement as personal and social interactive engagement. They found that they are causally related to consumer active and passive use of social media and suggested that advertisers need to explore the opportunities opened by social media to target users effectively because customers are looking for more interesting and engaging content that holds their interest. So in social media as a convenient communication tool, the users' socialization (social interaction refers to the gratifications from keeping in contact with friends and new acquaintances' forming and social integration refers to the gratifications from strengthening individual trust, sense of confidence, and connections with our acquaintances) will have some important implications for researching advertising avoidance. 


\subsection{Advertising Avoidance on mobile social platforms}

Compared with Internet advertising, mobile advertising faces unclear circumstances, and the research on mobile social advertising avoidance is scant. For this study, we investigated advertising on mobile social platforms as advertising that actively utilizes mobile social media techniques such as banner and message ads, brand applications, and videos on social media sites such as Facebook and KaKaotalk, in some extent distinguishing it from website-based Internet advertising. Mobile social advertising takes advantage of the features of mobile applications and social media by combining the two, but it also faces more than a few problems. One typical challenge is that improperly collecting personal information and search histories can lead to concern regarding privacy and spam. Another is that accessing mobile social media is highly goal directed, and inconvenient advertising campaigns that users perceive as impediments can lead to negative attitudes. Lee and Ahn [41] argued that on the internet all forms of advertising have a frequent exposure, but to consumers there exists most frequently ad avoidance. So we also propose that in the context of mobile social media, there exist a serious frequent advertising avoidance. Excessive advertising avoidance decreases ads' exposure to target consumers, reducing their effectiveness and moreover negatively affecting the related brands [31, 40]; thus research on mobile social advertising avoidance and its determinants is urgent. Our literature analysis revealed that negative attitudes such as irritation $[54,58]$ and perceived intrusiveness $[13,22,42]$, privacy concern [6, 59, 62], ad clutter [57], and perceived risk $[48,51]$ are primary determinants of advertising avoidance. Therefore, for this study based on the theory of reasoned action (TRA), we hypothesized that as a negative attitude, irritation would have a positive impact on advertising avoidance, and considering the features of and challenges with mobile social advertising, we studied the structural relationships between perceived intrusiveness, privacy concerns, and advertising avoidance. In a study of a web-advertising model, Ducoffe [20] defined advertising value as "a subjective evaluation of the relative worth or utility of advertising to consumers" and contended that it could serve as an index of customer satisfaction; the author conceived of ad value as a predictor of intentions and attitudes toward advertising. In a similar context, we aimed to determine the moderating effects of perceived advertising value on irritation and advertising avoidance in the context of mobile social advertising.

\subsection{U\&G for advertising on mobile social platforms}

Recent research has successfully incorporated uses and gratification theory to study social networking sites such as Facebook, Myspace, and Twitter [29, 65], and thus, we attempt to adapt $\mathrm{U} \& \mathrm{G}$ to investigate advertising on mobile social platforms. In the initial research on U\&G theory, Katz et al. redefined the theory of media effects to present U\&G theory as an understanding of audiences' motivations for selecting media and content based on gratification-seeking behaviors such as seeking information, social interaction, and entertainment and escapism from using media [33]. Other studies on digital advertising media have used U\&G theory as a framework to explore advertising effect $[6,36,39,53,62,67,69]$, but research combining mobile features and social features to exploit advertising avoidance on mobile social platforms is scanty. Following the relevant social networking research, we believed that the U\&G approach would be suitable for studying mobile social media, and we provided a theoretical framework for understanding what specifically drives users' adoption of mobile social advertising. Other researchers have employed U\&G to understand people's motivations for using specific Internet applications and to identify diverse applications based on the needs they gratify [8]. For this research, we studied the roles of U\&G in the context of mobile social advertising by dividing the theory into three components: convenience $U \& G$ based on applications' ubiquity and tailoring; content $U \& G$ based on advertising's informativeness and entertainment; and social U\&G based on social interaction and social integration.

\section{Theoretical background and Research Hypotheses}

\subsection{Advertising Avoidance}

Advertising avoidance can be defined as "all actions by media users that differently reduce their exposure to ad contents" [60]. The research on Internet advertisement avoidance indicates that the concept comprises mechanical, behavioral, and cognitive avoidance and that the degree of avoidance decreases from mechanical to behavioral to cognitive [34, 42]. Cognitive avoidance can be seen as a psychological defense mechanism whereby users intentionally 
ignore ads they are exposed to. Behavioral avoidance refers to removing or eliminating advertisements, and mechanical avoidance refers to using features or instruments to decrease exposure to advertisements [40]. We believed these three types of ad avoidance would be applicable in mobile social advertising as well: Specifically, mechanical avoidance would entail using settings to avoid receiving future messages ("Delete this message," "Don't show this message," etc.), behavioral avoidance means immediately deleting ads, and cognitive avoidance refers to paying no attention to or ignoring the messages.

\subsection{Irritation and Perceived Advertising Value}

The TRA "aims to explain the relationship between attitudes and behaviors within human actions." It predicts that individuals will act based on their preexisting attitudes and behavioral intentions [1]. Tsang et al. [63] showed that generally consumers have negative attitudes toward mobile advertising and the relationship between consumer attitudes and consumer behavior is direct in mobile advertising. For this research, we used irritation as a negative attitude; in the early research, Ducoffe et al.'s web-advertising model defined irritation as "the extent to which the advertising is messy and irritating to users" and tested the relationship with advertising value [21]. In Ducoffe et al.'s web-advertising model, advertising value was defined as a measure of advertising effectiveness and conceived it as a predictor of intentions and attitudes related to advertising. However, Kim et al [38] used irritation as an endogenous variable found that it did not significantly predict advertising value, but it had a significant effect on flow experience. So, we assume that irritation directly impacts on advertising avoidance on mobile social platforms and want to test the moderating effect of perceived advertising value as the following hypotheses.

Hypothesis 1: Irritation has a positive effect on advertising avoidance in mobile social advertising.

Hypothesis 2: Perceived advertising value alleviates the degree of the effect of irritation on advertising avoidance.

\subsection{Perceived Intrusiveness and Privacy Concerns}

Brehm developed the psychological reactance theory that "reactance is a motivational reaction to offers, rules, or regulations that threaten or eliminate specific behavioral freedoms and argues that reactance occurs when a person feels that someone or something is taking away his or her choice or limiting the range of alternatives" [4]. The perceived intrusiveness of advertising is a cognitive evaluation of the degree to which the advertisement interrupts individual goals [22], and we proposed that if advertisements are perceived as noise in the process of communication, psychological reactance will result [40]. Research has found that ad intrusiveness is associated with negative emotions and behaviors such as irritation and avoidance [22, 66]. So, we proposed the relationship between perceived intrusiveness and irritation showed in the following hypothesis.

Hypothesis 3: Perceived intrusiveness has a positive effect on irritation in mobile social advertising.

Privacy concerns in social media can be defined as SNS users' apprehension about the loss or abuse of their private information [61], and Serra Inci Celebi et al. argued that users who view or click advertisements in Facebook are concerned about losing their private information [6]. In research on mobile advertising, Cleff determined that consumers' privacy concern include receiving unsolicited advertising messages, personal data collection for marketing purposes, and deliberate theft of personal information [14]. In studies about location-based and SMS advertising, Dhar et al and Wei et al. contended that privacy concern had a negative impact on attitudes toward and responses to advertisements [16, 67]. So, we assume that privacy concerns directly impact on irritation in mobile social advertising as the following hypothesis.

Hypothesis 4: Privacy concerns have a positive effect on irritation in mobile social advertising.

\subsection{U\&G and Advertising Avoidance in Mobile Social Media}

In the mobile communication context, Cheng et al. studied engagement in mobile social networking by describing $U \& G$ based on effectiveness including technological convenience, information exchange, and social networking connectivity [9]. Woo and Kang studied the mobile social network service Twitter and extracted six elements of usage gratification: communication with others, instantaneity, relationship formation, the nature of short sentences, the nature of information, and the approach to famous people [50]. Separately, Auan-Haase and Yong compared Facebook and instant messaging based on U\&G elements such as passing the time, affection, fashion, sociability, and information [53], and Gerlich et al. argued that users share information with friends through Facebook applications to gratify their needs for social interaction [28]. However, little research has 
systematically and completely used $U \& G$ to study users' motivations for using mobile social media and apply it to study advertising avoidance on mobile social platforms. Therefore, considering the features of mobile social advertising, we attempted to divide the concept of $U \& G$ into convenience, content, and social U\&G to study the effects of advertising in the mobile social media context.

Ubiquity refers to access to information from any location at any time and has been highlighted as the most important and distinctive asset of mobile devices compared with PCs [2]. Shintaro et al. found that ubiquity consisted of temporal and spatial flexibility and explored the role of ubiquity in mobile advertising avoidance [51]. In this research, we surveyed active smart phone users and included context flexibility to define ubiquity. Some researchers of ubiquity have argued that with no consideration of consumers' privacy, unfair, deceptive, unsolicited messages such as spam make consumers feel threatened, leading to negative attitudes, whereas appropriate utilization of ubiquity, that is, supplying consumers with relevant messages at appropriate times even if some private information is exposed, leads to positive attitudes [51]. Recent evidence shows that consumers are increasingly conscious of privacy concern [49], and some researchers have argued that despite the utility of mobile devices, consumers may fear the possibility of information leakage and perceive a lack of control over unexpected intrusions [25]. In the context of mobile social media, we proposed that ubiquity would play a negative role in advertising by making advertisements available at any place and any time. Recently, the field of information systems communication has popularized personalization and customization as two distinct types of tailoring: Personalization emphasizes system-initiated tailoring whereby the system automatically tracks personal information and delivers ad content that matches users' preferences, whereas customization allow users to choose their ad categories based on their own preferences, emphasizing their flexibility [43]. Lee et al. have empirically investigated that customization and personalization take an opposite role for attitudes toward location-based advertising. Thus, based on ubiquity and tailoring, we proposed convenience U\&G to study the effects of advertising on mobile social platforms as the following hypotheses.

H5 a: Ubiquity has a positive effect on perceived intrusiveness in mobile social advertising.

H5b: Ubiquity has a positive effect on privacy concern in mobile social advertising.

H6 a : Personalization has a negative effect on perceived intrusiveness in mobile social advertising.
H6b: Personalization has a positive effect on privacy concern in mobile social advertising.

H7a: Customization has a positive effect on perceived intrusiveness in mobile social advertising.

$\mathrm{H} 7 \mathrm{~b}$ : Customization has a negative effect on privacy concern in mobile social advertising.

Some researchers have argued that advertising's primary legitimizing function is to give recipients useful information that helps them make decisions [55, 64]. Based on U\&G theory, Okazaki demonstrated that one value that advertising derives from its content is the ability to gratify basic entertainment, diversion, emotional release, and escapism needs, and Zhou and Bao, in studying web advertising, determined that entertainment has a positive relationship with attitudes toward advertising [50, 69]. Additionally, Gao and Koufaris argued that users' attitudes toward Internet advertising are determined by two qualities of ad content, informativeness and entertainment [27]. Therefore, for our research, we defined content U\&G based on informativeness and entertainment in mobile social advertising and proposed that the two would have negative impacts on perceived intrusiveness and privacy concerns as follows:

$\mathrm{H} 8 \mathrm{a}$ : Informativeness has a negative effect on perceived intrusiveness in mobile social advertising. H8b: Informativeness has a negative effect on privacy concern in mobile social advertising.

H9a: Entertainment has a negative effect on perceived intrusiveness in mobile social advertising.

H9b: Entertainment has a negative effect on privacy concern in mobile social advertising.

Donath argued that through online social network sites, users can create and perform personal identities and communities in social spaces [19]; when users have sufficient friends and quality relationships on social networking sites, they gain benefits of social interactions such as social status and popularity [10]. Ellison et al. and Zywcia et al. defined these benefits as social capital and social well-being and argued that they can motivate social media use $[10,23,70]$. Social capital refers to the benefits derived from social network relationships [15], and social well-being refers to global cognitive judgments of the self, which include self-esteem and life satisfaction [32]; Diener et al. argued that subjective social well-being is a positive emotion with important effects on personal identity [17, 18], and Helliwei and Putnam maintained that social capital is important for forming bond relationships with family and friends and thus has a positive effect on social well-being [32]. Based on these findings, we suggested social capital and social well-being as motivators of social media use and 
defined social U\&G as social interaction and social integration. Here, social interaction refers to the gratifications of keeping in contact with friends and forming new acquaintances, and social integration refers to the gratifications from strengthening individual trust and confidence and fostering one's own identity. Thus, to explore how social U\&G affect the effects of advertising on mobile social platforms, we proposed the hypotheses as follows:

H10a: Social interaction has a negative effect on perceived intrusiveness in mobile social advertising.

H10b: Social interaction has a negative effect on privacy concern in mobile social advertising.

H11a: Social integration has a negative effect on perceived intrusiveness in mobile social advertising.

H11b: Social integration has a negative effect on privacy concern in mobile social advertising.

\section{Research methodology}

\subsection{Research Model and Data collection}

Combining with TRA and early Ducoffe's web advertising model, we extract irritation as a negative attitude assume that it impacts on advertising avoidance with testing the moderating effect of perceived advertising value. Following the research on internet advertising and considering the features of mobile social media, we use perceived intrusiveness and privacy concerns as predictors of ad avoidance; in this way, we attempt to more deeply understand how advertising avoidance forms and how to alleviate it. As discussed above, we redefine $\mathrm{U} \& \mathrm{G}$ theory as dividing it into convenience, content and social $U \& G$ to achieve our study goal. Incorporate perceived intrusiveness and privacy concerns as determinants of advertising avoidance, our research model displayed in figure 1 .

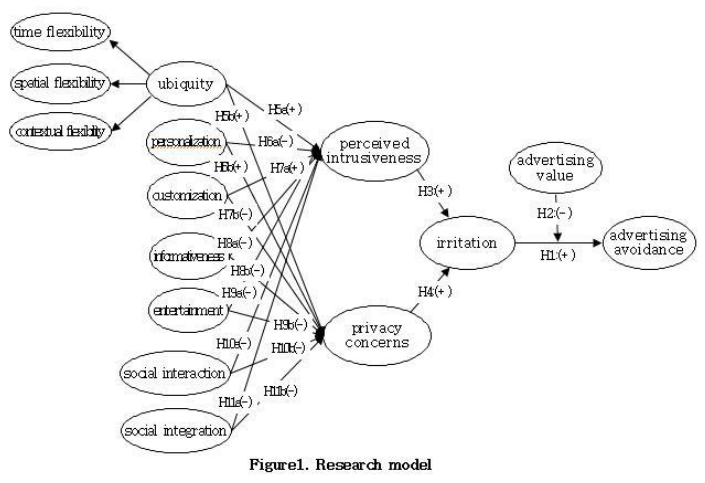

To investigate the research model, we conducted online and off-line surveys of active smart phone users in Korea and China from April 29 to May 19 in 2017.
The demographic analysis results based on 433 valid responses showed that $50.3 \%$ of the participants were male $(n=218)$ and $47.9 \%$ were female $(n=215)$. By age, $76.0 \%(n=329)$ were in their $20 \mathrm{~s}, 21.7 \%(n=94)$ in their $30 \mathrm{~s}$, and $1.1 \%(\mathrm{n}=5)$ each in their $40 \mathrm{~s}$ and $50 \mathrm{~s}$, and $97.2 \%$ had at least bachelor's degrees. Among all the participants, $87.3 \%$ reported using mobile social applications for over an hour per day, and $48.6 \%$ had some experience sharing mobile social advertisements; these results indicate high levels of mobile social application use. Because the participants were smart phone users in Korea and China, the mobile social media sites we studied were KakaoTalk ( $n=280$ users), Wechat $(n=115)$, Facebook $(n=115)$, and some others $(n=41)$. The types of mobile social advertisements participants reported having been exposed to were brand app ads $(30.7 \%)$, message ads $(30.7 \%)$, banner ads $(25.2 \%)$, video ads $(15.9 \%)$, text ads $(11.8 \%)$, and others (4\%). Advertising exposure was high: $71.6 \%$ of participants said they were exposed to ads more than three times per day.

\subsection{Data analysis}

We used previous studies as the foundations for the instruments we created and validated for this research. Before conducting confirmatory factor analysis (CFA), we performed exploratory factor analysis (EFA) and reliability analysis to test the validity and reliability of all the exogenous and endogenous variables using SPSS 22.0 (IBM Corporation, Armonk, NY, USA). To ensure the validity of the variables, we eliminated the measurement items with factor loadings less than 0.5. We then found that all of the factor loadings underlying the same variable were greater than 0.5 and larger than the other variables, and all the Cronbach's alphas were greater than 0.7 , confirming the internal consistency and validity of the variables.

Then, we calculated the validity of the exogenous and endogenous variables independently using CFA in AMOS 21.0 (IBM Corporation, Armonk, NY, USA). As shown in Table 1 and Table 2, all the observed indicators were statistically significant $(\mathrm{p}<0.05)$ and strongly loaded on their latent factors, ensuring convergent validity [24, 30]. We used AVEs (average variances extracted) and CRs (construct reliability) to assess the convergent and discriminant validity. Table 3 shows that the AVEs for all constructs were above the 0.5 cut-off, and all CRs were over 0.7 , which ensured convergent validity; meanwhile, the square roots of the AVEs were higher than their correlations with other constructs, ensuring discriminant validity [24, 30]. 
Table 1. Validity of the exogenous variables (CFA1)

\begin{tabular}{|c|c|c|c|c|c|c|c|}
\hline Factors & $\begin{array}{c}\text { Measurement } \\
\mathrm{s}\end{array}$ & $\begin{array}{c}\text { Coefficiei } \\
\text { nt }\end{array}$ & $\begin{array}{c}\text { Standardize } \\
d \\
\text { Coefficient }\end{array}$ & S.E. & $\begin{array}{c}\top \\
\text { Value }\end{array}$ & AVE & $\mathrm{CR}$ \\
\hline \multirow{3}{*}{ Ubiquity } & $\begin{array}{c}\text { Time } \\
\text { Flexibility }\end{array}$ & 0.781 & 0.475 & $\begin{array}{c}0.11 \\
1\end{array}$ & 7.012 & \multirow{3}{*}{$\stackrel{0.53}{9}$} & \multirow{3}{*}{$\begin{array}{c}0.72 \\
1\end{array}$} \\
\hline & $\begin{array}{l}\text { Spatial } \\
\text { Flexibility }\end{array}$ & 0.928 & 0.776 & $\begin{array}{c}0.11 \\
2\end{array}$ & 8.255 & & \\
\hline & $\begin{array}{l}\text { Context } \\
\text { Flexibility }\end{array}$ & 1 & 0.889 & & & & \\
\hline Time & UBts1 & 0.856 & 0.78 & 0.09 & 9.552 & 0.73 & 0.73 \\
\hline \multirow{2}{*}{$\begin{array}{c}\text { Spatial } \\
\text { Flexibility }\end{array}$} & $\begin{array}{l}\text { UBts3 } \\
\text { UBss1 }\end{array}$ & $\frac{1}{0.968}$ & 0.924 & 0.07 & 12.83 & \multirow[b]{2}{*}{0.64} & \multirow{2}{*}{$\begin{array}{c}0.73 \\
1\end{array}$} \\
\hline & UBst2 & 1.000 & 0.102 & 5 & 5 & & \\
\hline \multirow{3}{*}{$\begin{array}{l}\text { Context } \\
\text { Flexibility }\end{array}$} & UBcf2 & 0.999 & 0.821 & 0.06 & $\begin{array}{l}16.14 \\
8\end{array}$ & \multirow{3}{*}{$\begin{array}{c}0.64 \\
8\end{array}$} & \multirow{3}{*}{0.82} \\
\hline & UBcf3 & 1 & 0.746 & & & & \\
\hline & UBcf4 & 0.983 & 0.846 & 0.06 & $\begin{array}{l}16.46 \\
3\end{array}$ & & \\
\hline \multirow{3}{*}{$\begin{array}{c}\text { Personalizatio } \\
n\end{array}$} & TAps1 & 0.881 & 0.796 & 0.04 & 20.31 & \multirow{3}{*}{$\begin{array}{c}0.71 \\
7\end{array}$} & \multirow{3}{*}{0.75} \\
\hline & TAps2 & 1 & 0.889 & & & & \\
\hline & TAps3 & 0.933 & 0.854 & 0.04 & 22.64 & & \\
\hline \multirow[b]{2}{*}{ Customization } & TAct1 & 1 & 0.87 & & & \multirow{2}{*}{$\begin{array}{l}0.73 \\
8\end{array}$} & \multirow{2}{*}{$\begin{array}{c}0.72 \\
2\end{array}$} \\
\hline & TAct2 & 0.918 & 0.848 & 0.05 & 18.42 & & \\
\hline \multirow{3}{*}{$\begin{array}{c}\text { Informativenes } \\
\mathrm{s}\end{array}$} & IMif1 & 0.896 & 0.781 & 0.04 & 19.99 & \multirow{3}{*}{$\begin{array}{c}0.68 \\
9\end{array}$} & \multirow{3}{*}{0.74} \\
\hline & IMit2 & 1 & 0.892 & & & & \\
\hline & IMif4 & 0.959 & 0.813 & 0.04 & 21.40 & & \\
\hline \multirow{3}{*}{ Entertainment } & IMen2 & 0.947 & 0.916 & $\begin{array}{c}0.02 \\
6\end{array}$ & 36.53 & \multirow{3}{*}{$\begin{array}{c}0.88 \\
4\end{array}$} & \multirow{3}{*}{$\begin{array}{c}0.89 \\
1\end{array}$} \\
\hline & IMen3 & 1.013 & 0.955 & 0.02 & 43.17 & & \\
\hline & IMen4 & 1 & 0.95 & & & & \\
\hline \multirow{3}{*}{$\begin{array}{c}\text { Social } \\
\text { Interaction }\end{array}$} & SCsi3 & 0.96 & 0.755 & 0.05 & 18.07 & \multirow{3}{*}{$\begin{array}{c}0.68 \\
7\end{array}$} & \multirow{3}{*}{$\begin{array}{c}0.72 \\
5\end{array}$} \\
\hline & SCsi4 & 0.993 & 0.87 & 0.04 & 22.02 & & \\
\hline & SCsi5 & 1 & 0.857 & & & & \\
\hline \multirow{3}{*}{$\begin{array}{l}\text { Social } \\
\text { Integration }\end{array}$} & SCst1 & 0.937 & 0.867 & $\begin{array}{c}0.03 \\
6\end{array}$ & 26.04 & \multirow{3}{*}{$\begin{array}{c}0.71 \\
8\end{array}$} & \multirow{3}{*}{0.82} \\
\hline & $\begin{array}{l}\text { SCst2 } \\
\end{array}$ & 0.945 & 0.868 & 0.03 & 26.07 & & \\
\hline & SCst3 & 1 & 0.904 & & & & \\
\hline
\end{tabular}

Chi-square $=459.726(d f=245)$ GFI $=0.923, \mathrm{NFI}=0.945, \mathrm{CFI}=0.973$,

Normed Chi-square $=1.876$ RMSEA $=0.045$

SCst: social integration, IMen: entertainment, IMif: informativeness, SCsi: social interaction, TAps: personalization, UBcf: context flexibility, TAct: customization, UBts: time saving, UBsf: spatial flexibility

Table 2. Validity of the endogenous factors (CFA2)

\begin{tabular}{|c|c|c|c|c|c|c|c|}
\hline Factors & Measurements & Coefficient & $\begin{array}{c}\text { Standardized } \\
\text { Coefficient }\end{array}$ & S.E. & T Value & AVE & $\mathrm{CR}$ \\
\hline \multirow{3}{*}{$\begin{array}{l}\text { Perceived } \\
\text { Intrusiveness }\end{array}$} & Pl1 & 0.669 & 0.663 & 0.043 & 15.604 & \multirow{3}{*}{0.67} & \multirow{3}{*}{0.747} \\
\hline & $\mathrm{PI} 2$ & 1 & 0.929 & & & & \\
\hline & PI3 & 0.902 & 0.841 & 0.042 & 21.616 & & \\
\hline \multirow{5}{*}{ Irritation } & Al1 & 0.885 & 0.802 & 0.043 & 20.351 & \multirow{5}{*}{0.643} & \multirow{5}{*}{0.834} \\
\hline & $\mathrm{Al} 2$ & 1 & 0.859 & & & & \\
\hline & $\mathrm{Al} 3$ & 0.999 & 0.834 & 0.046 & 21.646 & & \\
\hline & $\mathrm{Al} 4$ & 0.9 & 0.792 & 0.045 & 19.838 & & \\
\hline & Al5 & 0.884 & 0.716 & 0.057 & 15.591 & & \\
\hline \multirow{4}{*}{$\begin{array}{l}\text { Advertising } \\
\text { Avoidance }\end{array}$} & AA1 & 1 & 0.817 & & & \multirow{4}{*}{0.617} & \multirow{4}{*}{0.8} \\
\hline & AA2 & 0.937 & 0.77 & 0.056 & 16.764 & & \\
\hline & AA3 & 0.91 & 0.774 & 0.06 & 15.227 & & \\
\hline & AA4 & 0.974 & 0.818 & 0.054 & 18.09 & & \\
\hline \multirow{2}{*}{$\begin{array}{l}\text { Privacy } \\
\text { Concern }\end{array}$} & PC3 & 1 & 0.76 & & & \multirow{2}{*}{0.623} & \multirow{2}{*}{0.585} \\
\hline & PC4 & 0.915 & 0.721 & 0.113 & 8.088 & & \\
\hline \multirow{3}{*}{$\begin{array}{l}\text { Advertising } \\
\text { Value }\end{array}$} & AL1 & 0.932 & 0.912 & 0.028 & 33.329 & \multirow{3}{*}{0.821} & \multirow{3}{*}{0.869} \\
\hline & AL2 & 1 & 0.963 & & & & \\
\hline & AL3 & 0.87 & 0.839 & 0.032 & 26.968 & & \\
\hline
\end{tabular}

Chi-square=190.2(df=103) GFI=0.949, NFI=0.961, CFI $=0.982$ Normed Chi-square $=1.847$ RMSEA $=0.044$

AI: irritation, AA: advertising avoidance, AL: perceived advertising value, PI: perceived intrusiveness, PC: privacy concern

Table 3. AVEs for discriminant and convergent validity

\begin{tabular}{|c|c|c|c|c|c|c|c|}
\hline & TAps & TAct & IMif & IMen & SCsi & SCst & UB \\
\hline $\begin{array}{c}\text { TAp } \\
\text { s }\end{array}$ & 0.846 & & & & & & \\
\hline TAct & $0.68^{* *}$ & 0.859 & & & & & \\
\hline IMif & $\begin{array}{c}0.728^{* *} \\
\star\end{array}$ & $\begin{array}{c}0.707^{* *} \\
\star\end{array}$ & 0.83 & & & & \\
\hline IMen & $\begin{array}{c}0.551^{* *} \\
\star\end{array}$ & $\begin{array}{c}0.534^{* *} \\
\star\end{array}$ & $\begin{array}{c}0.753^{* *} \\
\star\end{array}$ & 0.94 & & & \\
\hline
\end{tabular}

\begin{tabular}{|c|c|c|c|c|c|c|c|}
\hline SCsi & $\underset{*}{0.469^{* *}}$ & $0.572^{* *}$ & $0.667^{\star \star}$ & $0.706^{\star \star}$ & 0.828 & & \\
\hline SCst & $\underset{*}{0.623^{* \star}}$ & $0.573^{* *}$ & $0.698^{* \star}$ & $0.744^{* *}$ & $0.769^{* \star}$ & 0.843 & \\
\hline UB & $0.217^{\star \star}$ & $0.31^{\star \star \star}$ & $0.233^{* *}$ & 0.044 & $0.274^{* *}$ & ${ }^{0.252^{* \star}}$ & $\begin{array}{c}0.73 \\
4\end{array}$ \\
\hline
\end{tabular}

(two tailed): $* * * \mathrm{p}<0.001, * * \mathrm{p}<0.01, * \mathrm{p}<0.05$ diagonal elements are square root of average variance extracted

\begin{tabular}{|c|c|c|c|c|c|}
\hline & $\mathrm{PI}$ & $\mathrm{PC}$ & $\mathrm{AL}$ & $\mathrm{Al}$ & $\mathrm{AA}$ \\
\hline $\mathrm{PI}$ & 0.819 & & & & \\
\hline $\mathrm{PC}$ & $0.366^{\star \star \star}$ & 0.795 & & & \\
\hline $\mathrm{AL}$ & $0.179^{\star \star *}$ & -0.055 & 0.906 & & \\
\hline $\mathrm{Al}$ & $0.668^{\star \star \star}$ & $0.408^{\star \star \star}$ & $-0.371^{\star \star \star}$ & 0.802 & \\
\hline $\mathrm{AA}$ & $0.452^{\star \star *}$ & $0.479^{\star \star \star}$ & $-0.361^{\star \star \star}$ & $0.754^{\star \star *}$ & 0.785 \\
\hline
\end{tabular}

(two tailed): $* * * \mathrm{p}<0.001, * * \mathrm{p}<0.01,{ }^{*} \mathrm{p}<0.05$ diagonal elements are square root of average variance extracted

The goodness fit of structural equation model is acceptable: normed $\chi^{2}=1.85$, GFI $=0.883, \mathrm{NFI}=0.91$, CFI $=0.956$, RMSEA $=0.044[24,30]$. To test our hypotheses, we calculated whether the paths' coefficients were significant. Both perceived intrusiveness and privacy concerns had significant positive effects on irritation $(\beta=0.585, \mathrm{p}<0.001$; $\beta=0.251, p<0.001)$, and irritation had a significant positive effect on advertising avoidance $(\beta=0.698$, $\mathrm{p}<0.001$ ). Thus, hypotheses $\mathrm{H} 1$ and $\mathrm{H} 3, \mathrm{H} 4$ were supported.

To test the moderating effect of perceived advertising value on the relationship between irritation and advertising avoidance, we used the Chi-square method to test the differences between the constrained and free models for the participants divided by high $(\mathrm{n}=200)$ and low $(\mathrm{n}=233)$ perceived advertising value. Table 4 shows that there were no significant differences between the free and constrained models (normed $\chi_{(1,0.05)}^{2}=2.201<3.84, \mathrm{p}=0.138>0.05$ ) for either group: For the high perceived value group, the coefficient was $0.618(\mathrm{p}<0.001)$, and for the low group, it was $0.730(\mathrm{p}<0.001)$. Thus hypothesis $\mathrm{H} 2$ was rejected.

Table 4. Moderating effects of advertising value

\begin{tabular}{|c|c|c|c|c|c|c|c|c|}
\hline & Path & Coefficient & S.E. & C.R. & $P$ & DF & $x^{2}$ & $\begin{array}{c}\mathrm{P} \\
\text { value }\end{array}$ \\
\hline \multirow{2}{*}{$\mathrm{H} 4$} & $\begin{array}{l}\text { All-sAAA } \\
\text { (1liag) }\end{array}$ & 0.583 & 0.084 & 6.957 & $* * *$ & \multirow[b]{2}{*}{1} & \multirow{2}{*}{2.201} & \multirow{2}{*}{0.138} \\
\hline & $\begin{array}{c}\text { Al-mAA } \\
\text { (Low) }\end{array}$ & 0.757 & 0.081 & 9.308 & *** & & & \\
\hline
\end{tabular}

From the perspective of $U \& G$ theory, in the results for perceived intrusiveness and privacy concerns, we see that ubiquity had significant positive effects on both perceived intrusiveness $(\gamma=0.17, \mathrm{p}<0.05)$ and privacy concerns $(\gamma=0.364, \mathrm{p}<0.001)$, supporting hypotheses $\mathrm{H} 5 \mathrm{a}$ and $\mathrm{H} 5 \mathrm{~b}$. Personalization had a significant negative effect on perceived intrusiveness $(\gamma=-0.351, p<0.001)$ but a significant positive effect on privacy concerns $(\gamma=0.189, \quad \mathrm{p}<0.1)$, supporting hypotheses H6a and H6b as well. Customization had a significant positive effect on perceived intrusiveness $(\gamma=0.233, p<0.05)$ and a significant negative effect on 
privacy concerns $(\gamma=-0.196, p<0.1)$, and thus, hypotheses $\mathrm{H} 7 \mathrm{a}$ and $\mathrm{H} 7 \mathrm{~b}$ were supported. For social $\mathrm{U} \& \mathrm{G}$, social integration had a significant positive effect on perceived intrusiveness $(\gamma=0.291, p<0.05)$ and a significant negative effect on privacy concerns $(\gamma=-0.418, \mathrm{p}<0.01)$; thus, H11a was rejected but H11b was supported. Social interaction had a significant positive effect on privacy concerns only $(\gamma=0.327$, $\mathrm{p}<0.01$ ), in contrast to our propositions, and thus, hypotheses $\mathrm{H} 10 \mathrm{~b}$ and $\mathrm{H} 10 \mathrm{a}$ were rejected. Finally, for content $\mathrm{U} \& \mathrm{G}$, informativeness and entertainment had no significant effects on either perceived intrusiveness or privacy concerns, and thus we can say that all hypotheses H8a, H8b, H9a, and H9b were rejected. Figure 2 presents these results in graphical form.

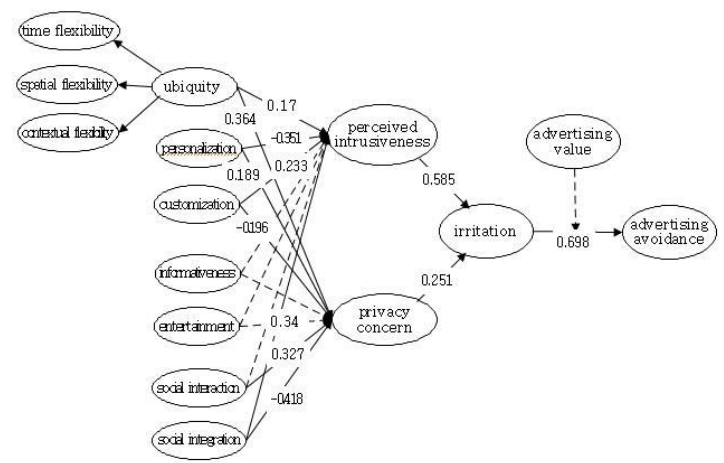

Figure2. Research model results

\section{Discussions and Contributions}

With the current widespread dissemination of mobile social media through our daily lives, mobile social advertising has been essential for advertisers. However, compared with the perfect market of internet advertising, mobile social advertising cannot keep pace with the rapid development of mobile social media, and many advertising strategies are not being utilized. Additionally, social media use on smart phone is highly goal-directed behavior, and a phenomenon called "banner blindness" can be easily resulted if users perceive ads as impediments to their task. For this research, we conduct a forming framework for advertising avoidance on mobile social platforms by focusing on negative attitude irritation and redefine $\mathrm{U} \& \mathrm{G}$ with an attempt to find an approach to alleviate advertising avoidance. Some management and theoretical contributions are discussed as follows.

Firstly, findings show that irritation directly affect advertising avoidance on mobile social platforms without moderating effect of perceived advertising value. From this result we can suggest that to enhance the effectiveness of advertising on mobile social platforms, advertisers should look for some interesting and engaging content that hold consumers' interest to decrease the irritation [52] rather than advertising frequently with a great deal no plan. Recent research argue that attitude toward advertising come positive to negative [26, 34, 41, 58, 63], so, some immediate advertising avoidance behavior may be induced by negative attitude toward advertising cannot be overlooked anymore.

Second, considering the features of mobile social media, we selected perceived intrusiveness and privacy concern as predictors of irritation. Based on psychological reactance theory [22] and IUIPC model [48], we proposed that perceived intrusiveness and privacy concern would have positive effect on irritation. Findings show that perceived intrusiveness with a higher coefficient to irritation than privacy concern takes a more important role. Therefore, to improve attitude toward advertising on mobile social platforms, strategies of advertising to targeted users at right time should be generated. From the perspective of convenience $U \& G$, we find that two types of tailoring customization and personalization take an opposite role on affecting perceived intrusiveness and privacy, in addition to the positive relationship between ubiquity and perceived intrusiveness and privacy concern. This will be very helpful for advertising strategies on mobile social platforms.

Besides that, there are also some theoretical contributions we can look forward. On one hand, research on advertising avoidance on mobile social platforms is scant. We conduct a forming framework by combining TRA and Docuffes' web-advertising model with test of moderating effect of perceived advertising value between irritation and advertising avoidance to investigate advertising avoidance on mobile social platforms can be seen as a development on advertising research. Another hand, redefining $\mathrm{U} \& \mathrm{G}$ dividing into convenience $\mathrm{U} \& \mathrm{G}$, content $\mathrm{U} \& \mathrm{G}$, social U\&G to explore an approach to alleviate the degree of advertising avoidance on mobile social platforms can be seen as a contribution for developing $\mathrm{U} \& \mathrm{G}$ theory.

\section{Limitations and Future Study}

Despite the interesting findings from this investigation, it is important to recognize some limitations and the need for additional research.

First, our survey sample was solely smart phone users and mainly based on college student (97.2\%) in South Korea and China, so the population representation for advertising user will be a problem. And there may be existing serious problems for 
common method bias without test common method variance for exogenous variables and endogenous variables, because the perception of advertising on mobile social platforms will be different with countries can induce some latent method bias.

Second, unfortunately the results of social U\&G are ambiguous, so in the future study a deep research for social interaction and social integration for advertising on mobile social platforms is necessary. In addition, a mediating effect of privacy concern on perceived intrusiveness can be developed to delve advertising avoidance's forming framework in the future.

This research was supported by Korea Research Foundation: Korea-EU Global Talent Mobility with a focus on STEAM education and Flipped learning in 2018

\section{References}

[1] Ajzen, I. The theory of planned behavior. Organizational behavior and human decision processes, 50, 2 (December 1991), 179-211.

[2] Balasubramanian, S.; Peterson, R. A.; and Jarvenpaa, S. L. Exploring the implications of $\mathrm{m}$-commerce for markets and marketing. Journal of the academy of Marketing Science, 30, 4 (September 2002), 348-361.

[3] Boudreau, K. E. Mobile advertising and its acceptance by American consumers. Management, (May 2013), Paper 2.

[4] Brehm, J. W.; Burke, W. W.; Lake, D. G.; and Paine, J. V. A theory of psychological reactance. Organization change: A comprehensive reader, (2009), 377-390.

[5] Business Wire. TBG digital releases data that shows Facebook rewards ads with social context. www.businesswire.com/news/home/20110609006210/en/TBGDigital-Releases-Data-Shows-Facebook-

Rewards\#.U6sLV2dOWUk/ (accessed on June 9, 2011). [6] Celebi, S. I. How do motives affect attitudes and behaviors toward internet advertising and Facebook advertising? Computers in Human Behavior, 51, (May 2015), 312-324.

[7] Chan, C. Marketing the academic library with online social network advertising. Library Management, 33, 8 (2012) 479-489.

[8] Chen, H. T. and Kim, Y. Problematic use of social network sites: The interactive relationship between gratifications sought and privacy concern. Cyberpsychology, Behavior, and Social Networking, 16, 11, (2013), 806-812.

[9] Cheng, Y.; Liang, J.; and Leung, L. Social network service use on mobile devices: An examination of gratifications, civic attitudes and civic engagement in China. new media \& society, 17, 7 (2015), 1096-1116.

[10] Chi, H. H. Interactive digital advertising vs. virtual brand community: Exploratory study of user motivation and social media marketing responses in Taiwan. Journal of Interactive Advertising, 12, 1 (Fall 2011), 44-61.

[11] Cho, C. H. Factors influencing clicking of banner ads on the WWW. CyberPsychology \& Behavior, 6, 2 (2003), 201-215.

[12] Choi, G. Y.; Jeong, Y. S.; Jeong, D. Y.; and Ahn, B. H. What factors affect on the advertising avoidance in the mobile SNS. Journal of Society for e-Business Studies, 15, 6 (2015), 169-189. [13] Choi, E. Y. and Do, S. J. The Roles of Internet Use Motivation and Ability, Advertising Perception, and General Attitude toward Advertising in the Internet Advertising Avoidance.
The Korean Journal of Advertising and Public Relations, 13, 2 (2011), 171-197.

[14] Cleff, E. B. Effective approaches to regulate mobile advertising: Moving towards a coordinated legal, self-regulatory and technical response. Computer Law \& Security Review, 26, 2 (March 2010), 158-169.

[15] Coleman, J. S. Social capital in the creation of human capital. American journal of sociology, 94, (1988), S95-S120.

[16] Dhar, S. and Varshney, U. Challenges and business models for mobile location-based services and advertising.

Communications of the ACM, 54, 5 (May 2011), 121-128.

[17] Diener, E. and Biswas-Diener, R. Findings on subjective wellbeing and their implications for empowerment. In Workshop on "Measuring Empowerment: Cross-Disciplinary Perspectives", World Bank, Washington DC, 2003, 6.

[18] Diener, E.; Suh, E.; and Oishi, S. Recent findings on subjective well-being. Indian journal of clinical psychology, 24, (March 1997), 25-41.

[19] Donath, J. Signals in social supernets. Journal of ComputerMediated Communication, 13, 1 (October 2007), 231-251.

[20] Ducoffe, R. H. Advertising value and advertising on the web. Journal of advertising research, 36, 5 (1996), 21-21.

[21] Ducoffe, R. H. How consumers assess the value of advertising. Journal of Current Issues \& Research in Advertising, 17, 1 (Spring 1995), 1-18.

[22] Edwards, S. M.; Li, H.; and Lee, J. H. Forced exposure and psychological reactance: Antecedents and consequences of the perceived intrusiveness of pop-up ads. Journal of Advertising, 31, 3 (Fall 2002), 83-95.

[23] Ellison, N. B.; Steinfield, C.; and Lampe, C. The benefits of Facebook "friends:" Social capital and college students' use of online social network sites. Journal of Computer-Mediated Communication, 12, 4 (July 2007), 1143-1168.

[24] Fornell, C., and Larcker, D. F. Evaluating structural equation models with unobservable variables and measurement error. Journal of marketing research, (February 1981), 39-50.

[25] Galanxhi, H. and Nah, F. F. H. Privacy issues in the era of ubiquitous commerce. Electronic markets, 16, 3 (2006), 222-232. [26] Gao, S. and Zang, Z. An empirical examination of users' adoption of mobile advertising in China. Information Development, 32, 2 (2016), 203-215.

[27] Gao, Y. and Koufaris, M. Perceptual antecedents of user attitude in electronic commerce. Acm Sigmis Database, 37, 2-3 (Spring-Summer 2006), 42-50.

[28] Gerlich, R. N.; Drumheller, K.; and Babb, J. App consumption: An exploratory analysis of the Uses \& Gratifications of mobile apps. Academy of Marketing Studies Journal, 19, 1 (2015), 69-79.

[29] Ha, Y. W.; Kim, J.; Libaque-Saenz, C. F.; Chang, Y.; and Park, M. C. Use and gratifications of mobile SNSs: Facebook and KakaoTalk in Korea. Telematics and Informatics, 32, 3 (2015), 425-438.

[30] Hair, J. F.; Black, W. C.; Babin, B. J.; Anderson, R. E.; and Tatham, R. L. Multivariate data analysis. Upper Saddle River, NJ: Prentice hall, 1998, 90-150, 604-761.

[31. Heeter, C. and Greenberg, B. S. Profiling the zappers. Journal of Advertising Research, 25, 2 (Apr-May 1985), 15-19.

[32] Helliwell, J. F. and Putnam, R. D. The social context of wellbeing. Philosophical Transactions of the Royal Society B: Biological Sciences, 359, (August 2004), 1435-1446.

[33] Katz, E.; Blumler, J. G.; and Gurevitch, M. Uses and gratifications research. The public opinion quarterly, 37, 4 (Winter 1973-1974), 509-523.

[34] Kelly, L.; Kerr, G.; and Drennan, J. Avoidance of advertising in social networking sites: The teenage perspective. Journal of interactive advertising, 10, 2 (March 2010), 16-27.

[35] Kim, B. H.; Soh, H. J.; and Lee, H. B. Advertisement in era of social media. Seoul: Communication Books, 2015. 
[36] Kim, J.; Lee, J.; Jo, S.; Jung, J.; and Kang, J. Magazine reading experience and advertising engagement: A uses and gratifications perspective. Journalism \& Mass Communication Quarterly, 92, 1 (January 2015), 179-198.

[37] Kim, J. W.; Lee, B. H.; Shaw, M. J.; Chang, H. L.; and Nelson, M. Application of decision-tree induction techniques to personalized advertisements on internet storefronts. International Journal of Electronic Commerce, 5, 3 (Spring 2001), 45-62. [38] Kim, Y. J. and Han, J. Why smartphone advertising attracts customers: A model of Web advertising, flow, and personalization. Computers in Human Behavior, 33, (2014), 256-269.

[39] Ko, H.; Cho, C. H.; and Roberts, M. S. Internet uses and gratifications: A structural equation model of interactive advertising. Journal of advertising, 34, 2 (Summer 2005), 57-70. [40] Lee, K. Y. The Effects of Attitudes on Mobile Advertising in Users' Avoidance Behavior. The e-Business studies, 11, 1 (March 2010), 95-119.

[41] Lee, J. and Ahn, J. H. Attention to Banner Ads and Their Effectiveness: An Eye-Tracking Approach. International Journal of Electronic Commerce, 17, 1 (Fall 2012), 119-137.

[42] Lee, J. A. and Lyu, J. Y. A Study of Advertising Avoidance in Internet: Level of Advertising Avoidance and Predictors of Advertising Avoidance. The Korean Journal of Advertising, 16, 1 (Spring 2005), 203-223.

[43] Lee, S.; Kim, K. J.; and Sundar, S. S. Customization in location-based advertising: Effects of tailoring source, locational congruity, and product involvement on ad attitudes. Computers in Human Behavior, 51, (May 2015), 336-343.

[44] Lee, W. J. Internet advertisement, Seoul: prunsasang, 2015. [45. Li, Y. M.; Lee, Y. L.; and Lien, N. J. Online Social Advertising via Influential Endorsers. International Journal of Electronic Commerce, 16, 3 (Spring 2012), 119-154.

[46] Li, Y.; Lin, L.; and Chiu, S. Enhancing Targeted Advertising with Social Context Endorsement. International Journal of Electronic Commerce, 19, 1 (Fall 2014), 99-128.

[47] Lin, T. T.; Paragas, F.; and Bautista, J. R. Determinants of mobile consumers' perceived value of location-based advertising and user responses. International Journal of Mobile Communications, 14, 2 (March 2016), 99-117.

[48] Malhotra, N. K.; Kim, S. S.; and Agarwal, J. Internet users' information privacy concern (IUIPC): The construct, the scale, and a causal model. Information systems research, 15, 4 (December 2004), 336-355.

[49] Navetta, D. Privacy legal risk environment shifts again. https://www.infosecisland.com/blogview/11456-Privacy-LegalRisk-Environment-Shifts-Again.html (accessed on March 11, 2011).

[50] Okazaki, S. Lessons learned from i-mode: What makes consumers click wireless banner ads? Computers in Human Behavior, 23, 3 (May 2007), 1692-1719.

[51] Okazaki, S.; Molina, F. J.; and Hirose, M. Mobile advertising avoidance: exploring the role of ubiquity. Electronic Markets, 22, 3 (May 2012), 169-183.

[52] Pagani, M. and Mirabello, A. The influence of personal and social-interactive engagement in social TV web sites. International Journal of Electronic Commerce, 16, 2 (Winter 2011-12), 41-68. [53] Quan-Haase, A. and Young, A. L. Uses and gratifications of social media: A comparison of Facebook and instant messaging. Bulletin of Science, Technology \& Society, 30, 5 (2010), 350-361. [54] Richard, J. E. and Meuli, P. G. Exploring and modeling digital natives' intention to use permission-based location-aware mobile advertising. Journal of Marketing Management, 29, 5-6 (2013), 698-719.

[55] Rotzoll, K. B.; Haefner, J. E.; and Hall, S. R. Advertising in contemporary society: Perspectives toward understanding. Illinois: University of Illinois Press, 1996.

[56] Sanz-Blas, S.; Ruiz-Mafé, C.; and Martí-Parreño, J. Messagedriven factors influencing opening and forwarding of mobile advertising messages. International Journal of Mobile Communications, 13, 4 (2015), 339-357.

[57] Seyedghorban, Z.; Tahernejad, H.; and Matanda, M. J. Reinquiry into advertising avoidance on the internet: A conceptual replication and extension. Journal of Advertising, 45, 1 (2016), 120-129.

[58] Sinkovics, R. R.; Pezderka, N.; and Haghirian, P. Determinants of consumer perceptions toward mobile advertising - a comparison between Japan and Austria. Journal of Interactive Marketing, 26, 1 (February 2012), 21-32. [59] Smit, E. G.; Van Noort, G.; and Voorveld, H. A. Understanding online behavioural advertising: User knowledge, privacy concern and online coping behaviour in Europe. Computers in Human Behavior, 32, (March 2014), 15-22. [60] Speck, P. S. and Elliott, M. T. Predictors of advertising avoidance in print and broadcast media. Journal of Advertising, 26, 3 (Fall 1997), 61-76.

[61] Taylor, D. G.; Lewin, J. E.; and Strutton, D. Friends, fans, and followers: do ads work on social networks? Journal of advertising research, 51, 1 (March 2011), 258-275.

[62] Tran, G. A. and Strutton, D. What Factors Affect Consumer Acceptance Of In-Game Advertisements? Journal of Advertising Research, 53, 4 (December 2013), 455-469.

[63] Tsang, M. M.; Shu-Chun, H.; and Ting-Peng, L. Consumer Attitudes Toward Mobile Advertising: An Empirical Study. International Journal of Electronic Commerce, 8, 3 (Spring 2004), 65-78.

[64] Tseng, F. C. and Teng, C. I. Carefulness Matters: Consumer Responses to Short Message Service Advertising. International Journal of Electronic Commerce, 20, 4 (Summer 2016), 525-550. [65] Weaver Lariscy, R.; Tinkham, S. F.; and Sweetser, K. D. Kids these days: Examining differences in political uses and gratifications, Internet political participation, political information efficacy, and cynicism on the basis of age. American Behavioral Scientist, 55, 6 (April 2011), 749-764.

[66] Wehmeyer, K. Mobile ad intrusiveness-The effects of message type and situation. BLED 2007 Proceedings, (2007), 6. [67] Wei, R.; Xiaoming, H.; and Pan, J. Examining user behavioral response to SMS ads: Implications for the evolution of the mobile phone as a bona-fide medium. Telematics and Informatics, 27, 1 (February 2010). 32-41.

[68] Wolff, M. The Facebook Fallacy. Technology Review, 115, 4 (2012). 70-72.

[69] Zhou, Z. and Bao, Y. Users= Attitudes Toward Web Advertising: Effects of Internet Motivation and Internet Ability. ACR North American Advances, 29, (2002), 71-78. [70] Zywica, J. and Danowski, J. The faces of Facebookers: Investigating social enhancement and social compensation hypotheses; predicting Facebook ${ }^{\mathrm{TM}}$ and offline popularity from sociability and self-esteem, and mapping the meanings of popularity with semantic networks. Journal of Computer-Mediated Communication, 14, 1 (October 2008), 1-34. 